\title{
Espécies arbóreas utilizadas por pescadores para a construção de jangadas, Área de Proteção Ambiental Costa de Itacaré-Serra Grande, Bahia, Brasil
}

\author{
Tree species used by fishermen for building handmade rafts, Environmental Protection Area \\ of Costa Itacaré-Serra Grande, Bahia, Brazil
}

Isis Leite Medeiros Mascarenhas Andrade ${ }^{1}$, Emerson Antônio Rocha Melo de Lucena ${ }^{1}$, Jorge Chiapetti ${ }^{2}$, Renata Camargo Asprino Pereira ${ }^{1}$ \& Marcelo Schramm Mielke $e^{1,3}$

\begin{abstract}
Resumo
Os jangadeiros são populações de pescadores artesanais das orlas marítimas que vivem no litoral nordeste brasileiro. O litoral sul da Bahia é uma das poucas regiões do litoral brasileiro onde a cultura viva da pesca com a jangada tradicional ainda persiste. O presente estudo teve como objetivo realizar o levantamento das espécies arbóreas utilizadas para a construção de jangadas tradicionais na região sul da Bahia, investigando as possíveis origens desse conhecimento mantido pelos pescadores artesanais. O levantamento foi realizado no distrito de Serra Grande, Uruçuca, Bahia, entre abril e maio de 2013, através de 13 entrevistas semi-estruturadas. Os resultados foram analisados de forma qualitativa. Um total de 13 espécies foram citadas. As espécies mais citadas foram Apeiba tibourbou (Malvaceae) e Albizia polycephala (Fabaceae). A continuidade do conhecimento acerca da pesca artesanal com jangadas vem sendo comprometida devido à dificuldade em extrair a matéria-prima. Foi detectada a introdução de um novo componente nas jangadas tradicionais, o motor, entre quatro a sete anos atrás. Os resultados obtidos nesse estudo demonstram a importância da relação da comunidade estudada com o meio em que vivem e das espécies utilizadas na confecção das jangadas, mantendo viva uma cultura que praticamente desapareceu em outras regiões. No entanto, são necessárias medidas urgentes para que essa cultura não desapareça em função de mudanças de hábitos e de dificuldades legais e logísticas para a obtenção de matéria-prima.

Palavras-chave: Conservação da biodiversidade, etnobotânica, Mata Atlântica.
\end{abstract}

\begin{abstract}
The "jangadeiros" are populations of artisanal fishermen of coastlines living in the northeastern Brazilian coast. Currently, it appears that only in some regions such as the southern coast of Bahia, the living culture of fishing with handmade rafts still persists. The present study aimed to survey tree species used for building handmade rafts in southern Bahia, investigating the possible sources of this knowledge kept by artisanal fishermen. The survey was conducted in the district of Serra Grande, Uruçuca, Bahia, between April and May 2013, through 13 semi-structured interviews. The results were analyzed qualitatively. A total of 13 species were cited. The most cited species are Apeiba tibourbou (Malvaceae) and Albizia polycephala (Fabaceae). The continuity of knowledge of artisanal fishing has been compromised due to the difficulty in extracting the raw material. A new component was introduced in traditional rafts, the engine, between four and seven years ago. The results of this study demonstrate the importance of the relationship of the community and the environment in which they live and the species used in the making of rafts, keeping alive a culture that disappeared in other regions. However, urgent actions are needed so that the culture does not disappear due to changes in habits and legal and logistical difficulties in obtaining raw materials.
\end{abstract}

Key words: Biodiversity conservation, ethnobotany, Atlantic Rainforest.

\footnotetext{
${ }^{1}$ Universidade Estadual de Santa Cruz, Depto. Ciências Biológicas, Rod. Ilhéus-Itabuna, Km 16, Salobrinho, 45662-900, Ilhéus, BA, Brasil.

${ }^{2}$ Universidade Estadual de Santa Cruz, Depto. Ciências Agrárias e Ambientais, Rod. Ilhéus-Itabuna, km 16, Salobrinho, 45662-900, Ilhéus, BA, Brasil.

${ }^{3}$ Autor para correspondência: msmielke@uesc.br
} 


\section{Introdução}

O Sul da Bahia é conhecido pela beleza da sua costa litorânea e pela exuberante presença de remanescentes da Mata Atlântica em elevado estágio de preservação e com alto grau de endemismo, conferindo-lhe uma extraordinária diversidade biológica (Martini et al. 2007). Ao longo da história a supressão das florestas nativas em áreas de Mata Atlântica tem sido constante (Dean 1996). Das áreas remanescentes poucas são primárias, havendo áreas de floresta plantada e uma grande parte de florestas secundárias em diversos estágios de regeneração (Galindo-Leal \& Câmara 2005). Embora a Mata Atlântica tenha sofrido grande supressão vegetal por ações antrópicas, na região sul da Bahia ainda existem grandes fragmentos de florestas conservadas e uma forte estratégia de conservação da biodiversidade, através da implementação de unidades de conservação, como a Área de Proteção Ambiental (APA) Costa de Itacaré - Serra Grande; as quais provocaram mudanças de atitudes das populações residentes em relação ao uso dos recursos naturais. Souza (2013) destacou a importante relação da APA Itacaré - Serra Grande com as comunidades humanas a ela associadas, tendo em vista a riqueza de espécies arbóreas e a intrínseca relação destas comunidades com os recursos florísticos.

Segundo decreto $\mathrm{n}^{\circ}$ 6.040, 7 de fevereiro de 2007, comunidades tradicionais são: "grupos culturalmente diferenciados e que se reconhecem como tais, que possuem formas próprias de organização social, que ocupam e usam territórios e recursos naturais como condição para sua reprodução cultural, social, religiosa, ancestral e econômica, utilizando conhecimentos, inovações e práticas gerados e transmitidos pela tradição". Diegues \& Arruda (2001) definem populações tradicionais como "grupos humanos diferenciados sob o ponto de vista cultural, que reproduzem historicamente seu modo de vida, de forma mais ou menos isolada, com base na cooperação social e relações próprias com a natureza”. Lessa (2007), utilizando um conceito mais abrangente, inclui, dentre outras, as comunidades indígenas, caiçaras, quilombolas, quebradeiras de coco, seringueiros, pescadores artesanais, etc.

Comunidades tradicionais de pescadores caracterizam-se pela preservação da cultura local, por meio de sua interação como o meio natural em que vivem para suprir suas necessidades básicas de sobrevivência. Baseado em suas tradições perpetuam modelos de vida distintos aos paradigmas sustentados pelos mercados atuais, onde o crescimento econômico é mantido pelo consumo de produtos muito além das necessidades humanas. Ao longo das muitas gerações, tais populações acumularam conhecimentos de sua natureza próxima, vivenciada, desenvolvendo capacidade ímpar de interferir no ambiente de forma sustentável (Nordi et al. 2001). Assim, a diversidade biológica vai sendo mantida de forma conjunta com a diversidade cultural dessas populações (Valentine et al. 2008).

O conhecimento das florestas e seu uso como recurso madeireiro para navegação fazem parte da história dessas comunidades. O Projeto Barcos do Brasil, desenvolvido pelo Instituto do Patrimônio Histórico e Artístico Nacional (IPHAN) (Brasil 2010), assinala que os barcos do Brasil fazem parte das paisagens tradicionais brasileiras e muitas vezes simbolizam cidades, estados ou regiões. Como exemplo disso, temos a jangada do nordeste brasileiro. Segundo o IPHAN, a origem da jangada vem de uma embarcação utilizada pelos índios, denominada de peri-peri, que após diversas adaptações introduzidas pelos europeus e africanos, transformou-se na jangada, embarcação adaptada para alto-mar com utilização de vela e leme. Registros da utilização da jangada são encontrados no início do século XVI, onde as mesmas eram utilizadas por escravos africanos para pesca na capitania de Pernambuco. A partir da década de 1950 houve um decréscimo no número de jangadas tradicionais existentes no nordeste brasileiro. Uma das hipóteses para a diminuição do seu uso para a atividade pesqueira é a dificuldade de encontrar a matéria-prima (pau-de-balsa, piúba ou pau-de-jangada) para a construção das embarcações. Atualmente, pode-se constatar que apenas em alguns lugares, como no sul da Bahia, onde ainda se encontram áreas de mata nativa, encontra-se o pau-de-jangada (Simões \& Lino 2003; Santana \& Fiamenge 2013).

De acordo com Santana \& Fiamenge (2013), no distrito de Serra Grande, Uruçuca, encontrase uma das cinco comunidades de pescadores jangadeiros da Bahia, sendo esse espaço mais utilizado pelo turismo do que por atividades que valorizem os produtos da pesca artesanal. A presença desta comunidade, a qual ainda mantém a tradição de pesca com jangadas vinculadas ao meio em que vivem nos motivou na escolha do tema da pesquisa. Nossa proposta é compreender como os pescadores artesanais mantêm e repassam 
esta importante tradição regional. Assim, torna-se de grande importância o testemunho e registro feitos pelas comunidades de jangadeiros, que guardam consigo parte da história e da cultura brasileira, dando continuidade à memorável tradição de construção e uso da jangada artesanal na atividade pesqueira.

Desta forma, o presente estudo teve como objetivo realizar um levantamento do conhecimento atual de uma população de jangadeiros do sul da Bahia sobre as espécies arbóreas utilizadas na construção de suas jangadas tradicionais, assim como investigar as possíveis origens do conhecimento mantido com esses pescadores artesanais.

\section{Materiais e Métodos}

\section{Área de estudo}

A Área de Proteção Ambiental (APA) Costa de Itacaré - Serra Grande totaliza 62.960,16 ha e está localizada na região Sul do Estado da Bahia, entre os meridianos $14^{\circ} 16^{\prime} 02^{\prime \prime}$ e 14 ' $^{\circ} 0^{\prime} 03^{\prime \prime}$ de Latitude Sul e 39॰5'18" e 38.58'38" de Longitude Oeste. A APA abrange os municípios de Ilhéus, Uruçuca e Itacaré, ocupando uma faixa litorânea de $28 \mathrm{~km}$ de extensão (SEMA 2013). Tanto a criação em 1993 quanto sua ampliação em 2003 vieram da necessidade em proteger os remanescentes de Mata Atlântica e os ecossistemas associados no entorno do Parque Estadual da Serra do Conduru (PESC), funcionando assim como zona de amortecimento dos impactos ambientais (Brasil 2004).

Comunidade estudada: pescadores artesanais (jangadeiros)

$O$ levantamento de informações foi realizado nas propriedades dos jangadeiros locais do distrito de Serra Grande, Uruçuca, Bahia, durante o período de abril a maio de 2013. Os informantes foram pescadores artesanais que utilizam ou utilizaram a jangada como meio de pesca e que residem no distrito de Serra Grande. A escolha deu-se de forma intencional, ou seja, uma amostra do tipo não probabilística, nos quais os elementos são selecionados baseados nas experiências e no conhecimento sobre o universo ao qual a pesquisa se destina (Albuquerque et al. 2010). O distrito de Serra Grande foi escolhido pelo fato de possuir uma das últimas comunidades de jangadeiros tradicionais remanescentes na região Nordeste do Brasil (Santana \& Fiamenge 2013).
Inventário etnobotânico

Como a pesquisa envolve a participação de pessoas, o projeto foi apreciado e aprovado pelo Comitê de Ética em Pesquisa com Seres Humanos da UESC, tendo o Certificado de apresentação para Apreciação Ética - CAAE: 07844513.1.0000.5526. Todos os jangadeiros que aceitaram participar da pesquisa assinaram o termo de consentimento livre e esclarecido (TCLE) em acordo com as exigências éticas do Comitê Nacional de Saúde (Resolução 196/96), autorizando a divulgação das informações fornecidas, respeitando os diferentes princípios éticos para pesquisas com seres humanos. As entrevistas foram registradas por vídeos e fotografias.

Apesquisa teve início com um reconhecimento da área e da população, para conhecimento histórico-cultural da comunidade e identificação dos informantes, através de entrevistas informais. Em seguida foram realizadas visitas durante cinco dias consecutivos, trabalhando diretamente com os jangadeiros, onde cada um indicava outros possíveis informantes. Para isso, lançamos mão como estratégia de pesquisa de campo das entrevistas semi-estruturadas contendo questões diretas para obtenção das informações a respeito das plantas arbóreas utilizadas pelos jangadeiros da região. Paralelamente foram feitas filmagens das conversas para captarmos a transmissão oral dos conhecimentos diversos (Alexiades 1996; Cotton 1996). Todas as informações obtidas através dos formulários foram complementadas e enriquecidas pelo uso de técnica investigativa, a turnê guiada (Alexiades 1996), onde um jangadeiro se dispôs a ajudar na coleta das espécies citadas. Essa técnica foi utilizada com o intuito de evitar erros na identificação de espécies, provenientes dos nomes populares das plantas, visto que o informante apontará in loco a espécie que ele mesmo citou (Albuquerque et al. 2010). Foram realizadas coletas de material botânico (flor e fruto), nos locais onde o informante apontou como lugar de obtenção das espécies. As identificações foram feitas com auxílio de bibliografia especializada e por comparação com os espécimes dos herbários HUESC e CEPEC. O material botânico coletado foi depositado no herbário da Universidade Estadual de Santa Cruz (HUESC).

Análise de dados

Ao final da etapa de campo ocorreu a análise e tabulação dos dados, adotando uma avaliação 
qualitativa de acordo com Petrini (2007). Para a realização da mesma, foram analisadas as famílias botânicas mais representativas, qual o uso mais citado, quais as utilizações referidas para cada espécie, as partes das plantas utilizadas e a forma de manejo destas. Essas informações foram apresentadas por meio de tabelas.

\section{Resultados}

\section{Caracterização socioeconômica}

Todos os 13 jangadeiros entrevistados eram do sexo masculino. Quanto à origem, todos os jangadeiros entrevistados são do estado da Bahia. Quatro são oriundos dos municípios de Ilhéus, Itacaré e Uruçuca, sendo seis naturais da própria comunidade de Serra Grande, Uruçuca e três têm origem de outras cidades da Bahia: Vitória da Conquista, Coaraci e Maraú. A pesca é a única fonte de renda para seis dos entrevistados e constitui a principal fonte de renda para três dos entrevistados; os outros quatro não apresentam a pesca como única ou principal fonte renda, sendo que, destes, um está aposentado, um se afastou da pesca por motivo de saúde e dois trabalham atualmente em terra. Do total, nove dos 13 jangadeiros entrevistados possuem filhos, totalizando 27 homens e 10 mulheres, dos quais, apenas seis homens trabalham com a pesca juntamente com o pai.

Origem e continuidade do conhecimento

De um total de 13 jangadeiros, três aprenderam a pescar com seu pai e, ou avô, todos os outros 10 com pescadores mais antigos. Dos nove jangadeiros que possuem filhos (totalizando 27 homens e 10 mulheres), 14 dos homens detém o conhecimento da pesca com a jangada, porém, apenas sete deles interessam-se pela atividade. Nenhuma das 10 mulheres detêm o conhecimento. Dez jangadeiros alegaram já ter passado o conhecimento para terceiros, sendo que quatro destes não possuem filhos. Sete jangadeiros entrevistados confeccionam sua própria jangada, seis deles confeccionam com ajuda de outro jangadeiro ou pagam pela confecção de sua jangada. Todos extraem das matas da região as árvores necessárias à fabricação de suas jangadas. A composição básica das jangadas ainda em uso pela comunidade estudada, conforme descrição dos entrevistados é apresentada na Tabela 1. Todos os jangadeiros entrevistados relataram a introdução de um novo componente na embarcação, o motor. Segundo eles, essa adaptação foi introduzida entre quatro e sete anos atrás.

\section{Espécies citadas}

Foram citadas 13 espécies, pertencentes a 11 famílias (Tab. 2). Duas espécies, Apeiba tibourbou e Albizia polycephala foram citadas por todos os entrevistados e três, Artocarpus heterophyllus, Calophyllum brasiliense e Caryocar brasiliense, foram registradas por apenas um dos entrevistados. Quanto a aplicação da madeira das espécies citadas na confecção das jangadas, foram registradas seis formas de uso na confecção: a canga, o lastro, o mastro, a carrinha, os tornos e os remos. Todas apresentaram um tempo estimado de uso igual ou superior a seis anos, exceto $A$. tibourbou, que dura aproximadamente três anos. Das 13 espécies citadas, oito foram coletadas, com números de depósito em herbário (Tab. 2). As demais espécies citadas não foram coletadas pelos motivos de ocorrerem apenas em áreas de mata mais distantes do litoral, ou serem muito difíceis de serem encontradas. Apesar de não terem sido coletadas, são espécies muito conhecidas no entorno de Serra Grande, ao exemplo do conduru (Brosimum rubescens), que dá nome à principal unidade de conservação de proteção integral da região, o Parque Estadual da Serra do Conduru $(<$ http://www.parquedoconduru.org/>).

\section{Discussão}

O patrimônio naval brasileiro é um dos mais ricos do mundo, sendo que os barcos tradicionais do Brasil representam uma grande parcela do patrimônio naval da humanidade (Brasil 2010). Apesar da importância cultural da jangada tradicional, poucos trabalhos foram escritos e publicados em relação ao tema. O livro "Jangada: uma pesquisa etnográfica" é um clássico de Luís da Câmara Cascudo, escrito originalmente para a Societé d'Études Historiques Dom Pedro II e, posteriormente, ampliado para o Serviço de Documentação do Ministério da Educação (Cascudo 1964). O livro relata a origem histórica e evolutiva da jangada, a qual teria vindo da Índia, mas fixada, com as características atuais e típicas, apenas em praias do Nordeste brasileiro. "A jangada comum, popular e típica, é a de seis paus" (Cascudo 1964); a mesma jangada utilizada atualmente pelos entrevistados. 
Tabela 1 - Componentes da jangada tradicional usada no sul da Bahia, Brasil, com suas descrições.

Table 1 - Components of the traditional raft used in southern Bahia, Brazil, with their descriptions.

\begin{tabular}{|c|c|}
\hline Componentes & Descrição \\
\hline Lastro & $\begin{array}{l}\text { Composto por seis toras, de } 7 \text { a } 8 \text { metros de comprimento ( } 35 \text { a } 40 \text { palmos), fixadas umas } \\
\text { nas outras lateralmente por meio de tornos. O lastro é subdividido em meios (as duas toras } \\
\text { centrais), bordos (as duas toras periféricas) e os papus (as duas toras localizadas entre os } \\
\text { meios e bordos), essas subdivisões se diferem através da diferença do diâmetro das toras } \\
\text { utilizadas. }\end{array}$ \\
\hline Mastro & $\begin{array}{l}\text { Confeccionado por uma tora de madeira de aproximadamente } 10 \text { metros de comprimento } \\
\text { usado como suporte para a vela, disposto verticalmente em relação ao lastro. }\end{array}$ \\
\hline Vela & De tecido, corte e cálculo triangular apropriado, fixada no mastro por meio de cordas. \\
\hline Espicha & Peça de madeira apoiada no mastro utilizada para abrir a vela. \\
\hline Canga & $\begin{array}{l}\text { Componente de madeira com três furos, no centro (para encaixe do mastro) e um em cada } \\
\text { extremidade (para o encaixe dos morões), disposto horizontalmente em relação ao lastro. }\end{array}$ \\
\hline Carrinha & $\begin{array}{l}\text { Feita com madeiras resistentes, para o apoio e equilíbrio do mastro, canga e vela. Localiza-se } \\
\text { sob o lastro horizontalmente. }\end{array}$ \\
\hline Morão & Duas estacas confeccionadas em madeira, apoiadas na carrinha para o suporte da canga. \\
\hline Pêa & Cordas utilizadas na fixação da carrinha, canga e morões. \\
\hline Remo de governo & Feito de madeiras pesadas. Dá a direção da embarcação. \\
\hline Remo de mão & $\begin{array}{l}\text { Maior em comprimento do que o remo de governo, confeccionado em madeira, utilizado para } \\
\text { o deslocamento da jangada. }\end{array}$ \\
\hline Torno & Estacas utilizadas para a fixação das toras do lastro \\
\hline Banca do motor & Caixa de madeira utilizada para proteção do motor. \\
\hline Motor & Última adaptação feita na embarcação. \\
\hline Banco & $\begin{array}{l}\text { Confeccionado de tábua e disposto horizontalmente ao lastro localizado na proa (parte da } \\
\text { frente da jangada). }\end{array}$ \\
\hline Banco do mestre & $\begin{array}{l}\text { Confeccionado de tábua e disposto horizontalmente ao lastro localizado na popa (parte traseira } \\
\text { da jangada) onde o mestre senta-se e governa a embarcação. }\end{array}$ \\
\hline
\end{tabular}

Na obra de Cascudo (1964) é relatado o aparecimento, em 1940, no Rio Grande do Norte, da jangada de tábuas. Esta informação também é relatada por Diegues \& Arruda (2001), os quais afirmam que nas décadas de 1910 e 1980 ocorreu o surgimento das jangadas de tábua, passando a substituir de forma gradativa as jangadas de pau, ou jangada tradicional. Contudo, esses autores relatam a existência da jangada tradicional somente em alguns lugares, como no sul da Bahia, associando essa existência às áreas de mata nativa (onde ainda se encontra o pau-de-jangada, matéria prima para a confecção da embarcação). Esta informação é corroborada pelos resultados obtidos nesse estudo, pois o instrumento utilizado para a pesca artesanal pelos jangadeiros ainda é, de forma geral, a jangada cujo lastro é confeccionado de pau-de-jangada (A. tibourbou) ou muanza ( $A$. polycephala).

Santana \& Fiamenge (2013) reforça essa constatação, alegando a existência no distrito de Serra Grande, Uruçuca, Bahia, de uma das poucas comunidades de jangadeiros da Bahia. Todavia, em entrevista com jangadeiro na obra "Aventuras dos Jangadeiros do Nordeste", de Caruso (2004) há a seguinte afirmação: "Hoje, infelizmente, esse tipo de jangada (jangada de piúba com seis toros) não existe mais, porque proibiram 
Tabela 2 - Relação de espécies citadas em entrevistas realizadas com 13 jangadeiros do sul da Bahia, Brasil (nome científico, família, número de citações, distribuição geográfica, componente, tempo de uso).

Table 2 - List of species mentioned in interviews with 13 jangadeiros in southern Bahia, Brazil (scientific name, family, number of citations, geographic distribution, component, time of use).

\begin{tabular}{|c|c|c|c|c|c|c|c|}
\hline Espécie & Família & $\begin{array}{l}\text { Nome } \\
\text { Popular }\end{array}$ & $\begin{array}{c}\mathrm{N}^{0} \\
\text { Herbário }\end{array}$ & $\begin{array}{l}\mathrm{N}^{\mathbf{o}} \text { de } \\
\text { citações }\end{array}$ & $\begin{array}{l}\text { Distribuição } \\
\text { geográfica }\end{array}$ & $\begin{array}{l}\text { Componente } \\
\text { da jangada }\end{array}$ & $\begin{array}{c}\text { Tempo } \\
\text { estimado } \\
\text { de uso } \\
\text { (ano) }\end{array}$ \\
\hline $\begin{array}{l}\text { Apeiba tibourbou } \\
\text { Aubl. }\end{array}$ & Malvaceae & Jangada & 19641 & 13 & nativa & lastro & até 3 \\
\hline $\begin{array}{l}\text { Anarcadium } \\
\text { occidentale L. }\end{array}$ & Anacardiaceae & Cajueiro & 19645 & 5 & nativa & canga & $>6$ \\
\hline $\begin{array}{l}\text { Artocarpus } \\
\text { heterophyllus Lam. }\end{array}$ & Moraceae & Jaqueira & 19647 & 1 & naturalizada & canga & $>6$ \\
\hline $\begin{array}{l}\text { Albizia polycephala } \\
\text { (Benth) Killip. ex } \\
\text { Record }\end{array}$ & Fabaceae & Muanza & 19640 & 13 & nativa & lastro & até 6 \\
\hline $\begin{array}{l}\text { Brosimum } \\
\text { rubescens Taub. }\end{array}$ & Moraceae & Conduru & - & 9 & nativa & mastro & $>6$ \\
\hline $\begin{array}{l}\text { Calophyllum } \\
\text { brasiliense } \\
\text { Cambess. }\end{array}$ & Calophyllaceae & Alandi & - & 1 & nativa & mastro & $>6$ \\
\hline $\begin{array}{l}\text { Caryocar } \\
\text { brasiliense } \\
\text { Cambess. }\end{array}$ & Caryocaraceae & Pequi & - & 1 & nativa & canga & $>6$ \\
\hline $\begin{array}{l}\text { Pogonophora } \\
\text { schomburgkiana } \\
\text { Miers ex Benth. }\end{array}$ & Peraceae & Cocão & 19642 & 2 & nativa & torno & até 6 \\
\hline $\begin{array}{l}\text { Eschweilera ovata } \\
\text { (Cambess.) Mart. ex } \\
\text { Miers }\end{array}$ & Lecythidaceae & Biriba & 19646 & 10 & nativa & torno & até 6 \\
\hline $\begin{array}{l}\text { Manilkara } \\
\text { salzmannii (A.DC.) } \\
\text { H.J. Lam. }\end{array}$ & Sapotaceae & Massaranduba & - & 2 & nativa & carrinha & $>6$ \\
\hline $\begin{array}{l}\text { Peltogyne } \\
\text { confertiflora (Mart. } \\
\text { ex Hayne) Benth. }\end{array}$ & Fabaceae & Roxinho & - & 2 & nativa & carrinha & $>6$ \\
\hline Annona glabra L. & Annonaceae & Cortiça & 19643 & 5 & nativa & canga & $>6$ \\
\hline $\begin{array}{l}\text { Tabebuia cassinoides } \\
\text { (Lam.) DC. }\end{array}$ & Bignoniaceae & Taipóca & 19644 & 2 & nativa & remo & $>6$ \\
\hline
\end{tabular}

a corte da árvore. Jangada de piúba, agora, só no museu.". Essa sentença condiciona, assim, a extinção da jangada de piúba com a proibição da extração da mesma. Situação que muito se assemelha ao que hoje vivenciam os jangadeiros locais do distrito de Serra Grande. Estes alegam que, além da dificuldade da profissão que envolve fatores naturais, o fator mais dificultoso dos 
últimos tempos é a forma de aquisição da matéria prima para a fabricação da embarcação. Situação ilustrada na fala de dois entrevistados:

Tem algo que o senhor queira falar sobre a realidade dos jangadeiros daqui da região?

No momento também é que o IBAMA não deixa a gente tirar o pau de jangada, se eles pegam a gente com o pau em cima do carro eles levam o carro e pronto. Com os paus e tudo. ... Dificulta muito é melhor a gente pára até de fazer a jangada, do que correr esse risco.

O senhor que vai atrás da madeira na mata?

É. E inclusive tá até difícil, nem os fazendeiros querem dar mais, com medo. E a gente agora assim não tá pegando. Tá muito dificil.

Sempre que você precisou fazer a jangada achou a madeira na mata?

Rapaz, acha!

E é dificil?

É meio difícil. Aqui por perto mesmo os donos das fazendas não querem deixar por causa do IBAMA. Muitos donos já falaram para a gente que é por causa do IBAMA mesmo... Até mesmo se os fazendeiros der, os caminhoneiros não quer ir buscar, com medo.

Apesar de terem relatado que sempre encontraram a madeira quando houve a necessidade desta, ressaltaram a dificuldade da prática, associando-a à fiscalização para o corte e transporte das mesmas. Muitos dos entrevistados se mostraram descontentes com todos os empecilhos que envolvem a confecção da jangada, alegando que se tivessem a oportunidade da substituição da jangada por alguma outra embarcação que lhes inspirem mais segurança, assim fariam. A maior parte da motivação para a pesca com a jangada vem em função do custo para obtenção dessa embarcação em relação a outras e pela segurança da pesca com a jangada (Caruso 2004). Esta citação é corroborada pelos entrevistados.

Porque a jangada pode dá tempestade e mesmo se ela virar nóis tem o casco dela para ficar em cima para sobreviver. Certa embarcação aí, quando ela fura no casco não tem como a gente ficar em cima dela.

Diferentemente da afirmação de Cascudo (1964) “O jangadeiro é filho de jangadeiro", o presente estudo mostra que apenas 6 dos 37 filhos de jangadeiros estão dando continuidade a essa tradição. Salienta-se, entretanto, que o fato de não ser mantida a tradição familiar não tem causado a perda da continuidade do conhecimento acerca da construção de jangadas tradicionais, visto que o conhecimento foi passado e vem sendo passado, em maior parte, por meio da relação mestrediscípulo. Relação também evidente na origem do conhecimento dos entrevistados, sendo que a maior parte adquiriu este conhecimento com jangadeiros mais velhos.

[...] Ai quando foi um dia, tinha um coroa lá que se chamava Legário, ai ele ia pescar perto da praia aí eu ia lá com ele, no começo eu enjoava muito, mas aí eu fui crescendo, me acostumando e fui pescando mais fora.

E aprender a fazer, eu aprendi porque lá tinha o avô do meu filho que era mestre em fazer jangada. Ele fazia a jangada e às vezes ele ia fazer a jangada e eu ficava lá mais ele, ajudando ele, segurando um pau, ai ele botava o pau e eu ficava reparando como ele botava, ai depois eu mandei ele fazer uma jangada para mim. Ele fez a jangada, aí depois eu digo: "Eu mesmo vou fazer minha jangada.» Ai depois eu mesmo comecei a fazer a jangada $[\ldots]$

Cascudo (1964) relata que a jangada nordestina, com sua vela triangular, remo de governo e bolina (elementos essenciais na evolução posterior à vinda dos europeus), é uma solução única no mundo "igual ao seu tipo não consta em qualquer outro lugar". A jangada, com suas modificações através do tempo, sobreviveu e resistiu. Shepard Forman (1970), em seu livro "The raft fishermen", através da observação numa vila de jangadeiros, em Coqueiral, no litoral de Alagoas, destacou mudanças sociais e da tradição que ocorriam de forma vagarosa (apud Diegues \& Arruda 2001). A partir dos dados obtidos nesse estudo, podemos observar que as adaptações de fato têm grande parcela na sobrevivência da jangada. $\mathrm{O}$ motor introduzido de 4 a 7 anos atrás, por exemplo, demonstra claramente a modernização da embarcação no decorrer do tempo. Esta adaptação assegura a pesca com a jangada como algo viável em relação aos barcos motorizados, garantindo um maior proveito do tempo no pesqueiro (local onde ocorre a pesca).

Rondón (2003) em um trabalho similar, com a utilização de espécies vegetais utilizadas na 
confecção de balsas por uma comunidade indígena do Peru, constatou o uso de quatro diferentes espécies. Enquanto que neste constatamos o uso de 13 espécies diferentes na confecção da jangada tradicional. De acordo com Cascudo (1964), das 13 espécies citadas, apenas o cajueiro ( $A$. occidentale), o pau-de-jangada (A. tibourbou) e o conduru ( $B$. rubescens) foram semelhantes às espécies utilizadas na construção de jangadas em Fortaleza, CE. O pau-de-jangada (A. tibourbou) e a muanza ( $A$. polycephala) foram citadas por todos os entrevistados enfatizando a importância destas espécies na fabricação da jangada. Já a biriba ( $E$. ovata) e o conduru também tiveram uma representatividade bastante grande. Todas as espécies citadas são encontradas nas proximidades da comunidade de Serra Grande e nativas do sul da Bahia, exceto a jaqueira (A. heterophyllus) que é exótica, sendo nativa do sudeste asiático (Abreu \& Rodrigues 2010). Dentre as espécies citadas, a muanza (A. polycephala) merece destaque, pois, de acordo com as referências consultadas (Cascudo 1964; Caruso 2004), apenas no nosso estudo ela foi citada, e substitui perfeitamente o pau-de-jangada ( $A$. tibourbou). Ela é preferida pela maioria dos jangadeiros pelo fato ter uma maior durabilidade, deixando-os longe da mata por mais tempo.

Gualberto (2009) destaca que o envelhecimento das gerações acarreta em uma perda significativa dos saberes. "Saberes esses que não se circunscrevem apenas em técnicas de construção naval, mas estão atrelados a valores culturais, que contribuem tanto para a perpetuação da tradição quanto para a formação do cidadão." Assim, torna-se clara a singularidade da relação da comunidade estudada com o meio em que vivem, evidenciando que as atitudes tomadas em relação a este meio interferem diretamente não só com um estilo de vida, mas com toda uma identidade cultural que vem sendo preservada durante o decorrer da história até a atualidade.

\section{Considerações Finais}

A comunidade do distrito de Serra Grande, Uruçuca, BA, é, provavelmente, uma das últimas a guardar os conhecimentos da construção e utilização da jangada tradicional, visto que esta cultura permanece viva com os pescadores artesanais da região. Os resultados obtidos nesse estudo demonstram a importância da relação da comunidade estudada com o meio em que vivem e das espécies utilizadas na confecção das jangadas tradicionais. No entanto, são necessárias medidas urgentes para que essa cultura não desapareça em função de mudanças de hábitos e de dificuldades legais e logísticas para a obtenção de matéria-prima.

\section{Agradecimentos}

Os autores agradecem o apoio logístico da Universidade Estadual de Santa Cruz (UESC), aos funcionários do Instituto Floresta Viva (IFV), o auxílio prestado durante a coleta de dados, e a Associação de Pescadores de Serra Grande-BA, o tempo e informações concedidas. Marcelo S. Mielke agradece ao Conselho Nacional de Desenvolvimento Científico e Tecnológico (CNPq) a concessão de bolsa de produtividade em pesquisa. Parte dessa pesquisa realizada com recursos do projeto "Otimização do sistema de produção de mudas florestais no Viveiro Comunitário Floresta Viva, Serra Grande, BA", UESC, IFV e CNPq (Processo 561933/2010).

\section{Referências}

Abreu, R.C.R. de \& Rodrigues, P.J.F.P. 2010. Exotic tree Artocarpus heterophyllus (Moraceae) invades the Brazilian Atlantic Rainforest. Rodriguésia 64: 677- 688 .

Albuquerque, U.P.; Lucena, R.F.P. \& Cunha, L.V. F.C. 2010. Métodos e técnicas na pesquisa etnobiológicos e etnoecológica. Editora Livro Rápido/NUPPEA, Recife. 559p.

Alexiades, M.N. 1996. Selected guidelines for etnobotanical research: a field manual. The New York Botanical Garden, New York. 306p.

Brasil. 2004. Ministério do Meio Ambiente. Revisão do zoneamento ecológico-econômico: APA Costa de Itacaré-Serra Grande. Ilhéus. Disponível em $<$ http:// www.inema.ba.gov.br/wp-content/uploads/2011/09/ Zoneamento-Revisão-Itacaré-Serra-Grande1.pdf>. Acesso em 13 maio 2013.

Brasil. 2010. Ministério da Cultura e Pesca e Aquicultura. Projeto Barcos do Brasil. Instituto do Patrimônio Histório e Artístico Nacional - IPHAN, Brasília. 34p.

Caruso, R.C. 2004. Aventuras dos jangadeiros do Nordeste e as grandes viagens para o Rio de Janeiro, Ilhabela e Buenos Aires. Panam Edições Culturais, Florianópolis. 350p.

Cascudo, L. C. 1964. Jangada: uma pesquisa etnográfica. $2^{a}$ ed. Editora Letras e Artes, Rio de Janeiro. 165p.

Cotton, C.M. 1996. Ethnobotany: principles and applications. John Wiley \& Sons, New York. 424p.

Dean, W. 1996. A ferro e fogo - A história e a devastação da Mata Atlântica brasileira. Companhia das Letras, São Paulo. 484p. 
Diegues, A.C.S. \& Arruda, R.S. V. 2001. Saberes tradicionais e biodiversidade no Brasil. Ministério do Meio Ambiente, Brasília. 176p.

Galindo-Leal, C. \& Câmara, I. de G. 2005. Status do hotspot Mata Atlântica: uma síntese. Mata Atlântica: biodiversidade, ameaças e perspectivas. Galindo-Leal, C \& Câmara, IG (eds.). Fundação SOS Mata Atlântica, Conservação Internacional, Centro de Ciências Aplicadas à Biodiversidade, Belo Horizonte. 472p.

Gualberto, A.J.P. 2009. Embarcações, Educação e Saberes Culturais em um Estaleiro Naval da Amazônia. Dissertação de Mestrado. Universidade do Estado do Pará, Belém. 149p.

Lessa, C.M. 2007. Identificação de áreas prioritárias para a conservação da sociobiodiversidade da zona estuarina da Costa do Dendê, Bahia. Dissertação de Mestrado. Universidade de Brasília, Brasília. $125 \mathrm{p}$.

Martini, A.M.Z.; Fiaschi, P.; Amorim, A.M. \& Paixão, J.L. 2007. A hot-point witin a hot-spot: a high diversity point in Brazil's Atlantic Forest. Biodiversity and Conservation 16: 3111-3128.

Nordi, N.; Thé A.P.G. \& Mourão, J.S. 2001. Etnoecologia, educação ambiental e desenvolvimento sustentável. In: Santos, J.E. \& Sato, M. (orgs.). A contribuição da educação ambiental à esperança de Pandora. RIMA, São Carlos. Pp. 133-144.
Petrini, G. 2007. Políticas sociais dirigidas à família. In: Borges, A.; Castro, M. (org.). Família, gênero e gerações: desafios para as políticas sociais. Paulinas, São Paulo. Pp. 207-231.

Rondón, X.J.; Banack, S.A. \& Diaz-Huamanchumo, W. 2003. Ethnobotanical investigation of caballitos (Schoenoplectus californicus: Cyperaceae) in Huanchaco, Peru. Economic Botany 57: 35-47.

Santana, L.C. \& Fiamenge, E.C. 2013. Infância e meio ambiente: O conhecimento das crianças de Serra Grande sobre os peixes e mar. Cadernos CERU 24: 169-197.

SEMA - Secretaria de Meio Ambiente do Estado da Bahia. Decreto No 2186 de 07 de junho de 1993. Disponível em <http:// www.meioambiente. ba.gov.br>. Acesso em 12 maio 2013.

Simões, L.L. \& Lino, C.F. (orgs.). 2003. Sustentável Mata Atlântica: a exploração de seus recursos florestais. Editora Senac, São Paulo. Pp. 202-215.

Souza, N.A. 2013. Conhecimento etnobotânico de espécies arbóreas por agricultores da Área de Proteção Ambiental Costa de Itacaré/Serra Grande, Bahia, Brasil. Dissertação de Mestrado. Universidade Estadual de Santa Cruz, Ilhéus. 83p.

Valentine, C.M.A.; Almeida, J.D.; Coelho, M.F.B. \& Rodríguez-Ortiz, C.E. 2008. Uso de Siparuna guianensis Aublet (negramina) em Bom Sucesso, município de Várzea Grande, Mato Grosso. Revista de Biologia Neotropical 5: 11-22. 
